\title{
ROLE OF ANTI-HELICOBACTER PYLORI THERAPY IN IRON DEFICIENCY ANAEMIA- A PROSPECTIVE STUDY
}

\author{
Abdul Shahid Poovathum Parambil ${ }^{1}$, Shaiji Panthiyil Shahulhameed ${ }^{2}$ \\ ${ }^{1}$ Assistant Professor, Department of General Medicine, Division of Oncology, Andaman and Nicobar Islands Institute of Medical \\ Sciences, Port Blair, Andaman and Nicobar Islands. \\ ${ }_{2}^{2}$ Assistant Professor, Department of Transfusion Medicine, Government Medical College, Trivandrum.
}

\section{ABSTRACT}

\section{BACKGROUND}

Accumulating evidence suggests that Helicobacter pylori (H. Pylori) infection account for many unexplained cases of Iron Deficiency Anaemia (IDA), which may benefit from testing and treatment for H. pylori infection. This study attempts to evaluate the role of anti $\mathrm{H}$. pylori treatment in management of iron deficiency anaemia among patients treated at a tertiary care centre in North India.

\section{MATERIALS AND METHODS}

This was a prospective study which included 60 patients with IDA, proven positive for H. pylori by Rapid urease test and histopathological staining. They were divided into three groups $(n=20)$ and received different treatments, i.e. only anti-H. pylori therapy/ oral iron therapy plus anti-H. pylori therapy/ only oral iron therapy. Haemoglobin, RBC indices, Reti count, S. iron and S. ferritin were compared at the end of treatment with One-Way ANOVA.

\section{RESULTS}

At the end of our study, we observed that there is significant increase in $\mathrm{Hb}$ in patients treated with anti-H. pylori therapy single or in combination compared to patients only on oral iron therapy $(\mathrm{p}<0.001)$. Maximum improvement in Hb was observed in treatment group receiving both oral iron and anti-H. pylori treatment and it was significant compared to other two groups ( $\mathrm{p}<$ 0.001).

\section{CONCLUSION}

This study is definitely suggesting significant role of chronic $\mathrm{H}$. pylori gastritis as a cause of refractory IDA. Therefore, we suggest in all cases of refractory or chronic IDA patient must be investigated for the presence of H. pylori gastritis.

\section{KEYWORDS}

Helicobacter Pylori, Iron Deficiency Anaemia, Haemoglobin, Treatment.

HOW TO CITE THIS ARTICLE: Parambil ASP, Shahulhameed SP. Role of anti-helicobacter pylori therapy in iron deficiency anaemia- a prospective study. J. Evolution Med. Dent. Sci. 2017;6(81):5692-5697, DOI: 10.14260/jemds/2017/1235

\section{BACKGROUND}

Iron deficiency is in fact the commonest nutritional disorder worldwide as recognised by the WHO. ${ }^{1}$ An astounding 2000 million people, a third of the world's population are anaemic, and at least half due to iron deficiency. The diagnosis, treatment and prevention of iron deficiency are simple, cheap and effective. Yet why this epidemic still exists in such a majority of population is a matter of concern to physicians and nutritionists all over the world. It is estimated that for every one person with iron deficiency anaemia (IDA), there are another two with iron deficiency alone. ${ }^{2}$

The impact of iron deficiency is much common and devastating in all the populations, especially those who have the greatest requirements; pregnant women and children. ${ }^{3}$ In

'Financial or Other Competing Interest': None.

Submission 03-09-2017, Peer Review 28-09-2017,

Acceptance 03-10-2017, Published 09-10-2017.

Corresponding Author:

Dr. Abdul Shahid Poovathum Parambil,

Assistant Professor,

Department of General Medicine,

Division of Oncology,

Andaman and Nicobar Islands Institute of

Medical Sciences, Port Blair.

E-mail: abdulshahidpp@gmail.com

DOI: $10.14260 /$ jemds $/ 2017 / 1235$ developing countries, $54 \%$ of pregnant women suffer from anaemia compared to $18 \%$ in industrialised countries. Iron deficiency is also associated with an increased susceptibility to infection and decreased regulation of body temperature. Also concerning is the permanent cognitive impairment that occurs as well. There is a correlation between anaemia and lower IQ test scores by up to 15 points. Therefore, iron deficiency can significantly impair an individual's physical and intellectual capacity and as a consequence the national economy.

Refractory IDA accounts for about $15 \%$ of all IDAs. Since commonest causes of IDA is haemorrhage, gastroenterologists are frequently asked to perform endoscopic evaluation of patients with iron deficiency to determine if mucosal lesions causing chronic blood loss are present including neoplasms, ulcers and angiodysplasias. Despite a thorough clinical and endoscopic evaluation, large case series have shown that more than one-third of patients do not have a lesion to account for their iron deficiency emphasising the existence yet unrecognised causes of iron deficiency.

Accumulating evidence suggests that Helicobacter pylori (H. pylori) infection account for some of these unexplained cases of iron deficiency, i.e. H. pylori gastritis without peptic ulcer can be associated with low iron stores and anaemia. Further data is available that patients with unexplained IDA 
benefit from testing and treatment for $\mathrm{H}$. pylori infection. Epidemiologic studies also support an association between $\mathrm{H}$. pylori infection and low iron stores and several reports have shown resolution of refractory cases of anaemia after $\mathrm{H}$. pylori treatment. Given the relative ease and simplicity of $\mathrm{H}$. pylori treatment and the encouraging results in literature, $\mathrm{H}$. pylori testing and treatment for persons with unexplained IDA appears to be clinically indicated.

Helicobacter pylori may be the most common infectious disease worldwide. It is a ubiquitous organism that spares no part of the globe. Overall, nearly $50 \%$ of the world's population is although in some developing countries the prevalence is as high as $80 \%-90 \%$, whereas in the US $35 \%-40 \%$ of the population is infected. The postulated mechanisms by which $\mathrm{H}$. pylori causes IDA are multiple.

1. Increased iron loss due to active bleeding secondary to gastritis,

2. Achlorhydria resulting in reduced iron absorption, and

3. Iron utilisation by the bacterium.

Though IDA is quite commonly seen in North India and especially in the Aligarh region, but there is dearth of literature to establish H. pylori as a cause of IDA. Therefore, we undertook this study to find out the quantum of $\mathrm{H}$. pylori associated IDA and effect of $H$. pylori eradication on the outcome of such cases in Aligarh region.

\section{MATERIALS AND METHODS}

The present work was a two-year randomised controlled study. Patients attending Medicine and Gastroenterology, OPD of JN Medical College, AMU, Aligarh, were recruited in the study if they fulfilled the criteria.

\section{Inclusion Criteria}

1. Age $>10$ yrs. and $<60$ yrs.

2. Anaemia defined by $\mathrm{Hb}<11 \mathrm{gm} \%$ and peripheral smear suggestive of iron deficiency anaemia.

3. Endoscopic biopsy positive for Helicobacter pylori.

\section{Exclusion Criteria}

1. Those with stool positive for occult blood and hookworm ova.

2. Those with gastric ulcer/ duodenal ulcer and malignancy.

3. Those with history of consumption of NSAIDS and Corticosteroids.

4. History of blood transfusion in past three months.

5. Those with other obvious causes of anaemia.

Selected Patients underwent detailed History and Physical Evaluation. They were subjected to Following Investigations-

1. Haemogram, general blood picture and ESR.

2. $\mathrm{RBC}$ indices including MCV, MCH, MCHC.

3. Reticulocyte count.

4. Serum iron and serum ferritin.

5. Stool examination for ova cyst and occult blood.

6. Endoscopic evaluation.

7. Rapid urease test and Histopathological examination for Helicobacter pylori.

\section{Study Design}

This is a Randomised Controlled Trial conducted on patients attending Medicine and Gastroenterology OPD of a tertiary care institution (J. N. Medical College Hospital, AMU, Aligarh), of either gender, more than 10 years of age, diagnosed to be IDA with proven Helicobacter pylori infestation and fulfilled all inclusion criteria. The protocol of the study was approved by The Board of Studies and Ethical Committee of the Institute. A written consent was obtained from the patients who were finally included in the study. Sample size was calculated assuming a power of $80 \%, 95 \%$ confidence interval and a minimum clinically significant difference in haemoglobin of $1 \mathrm{~g} \%$.

These patients with IDA were subjected to Oesophagogastroduodeno-endoscopic evaluation after an informed consent and multiple biopsy samples were taken for in house rapid urease test. Tissue sections were stained for $\mathrm{H}$. pylori with $\mathrm{H}$ and $\mathrm{E}$ and Giemsa staining. Patients proven positive for Helicobacter pylori by Rapid urease test and histopathological staining were divided into three groups randomly using computer generated sequence.

Group 1- Received only anti-H. pylori therapy for the first two weeks.

Group 2- Received oral iron therapy for three months, but anti-H. pylori therapy was added for 2 weeks only in the second month.

Group 3- Received only oral iron therapy for three months.

Anti-H. pylori therapy was defined as clarithromycin 500 mg bid, lansoprazole $30 \mathrm{mg}$ bid and amoxicillin $1 \mathrm{gm}$ bid for 2 weeks.

Oral iron therapy was defined as oral ferrous sulfate tablets $200 \mathrm{mg}$ thrice a day for 3 months.

After completion of study period (i.e. 3 months) oral iron therapy and anti-H. pylori therapy was provided to Group 1 and Group 3 respectively.

A baseline evaluation of Haemoglobin, RBC indices, Reti count, S. iron and S. ferritin were done. Haemoglobin ( $\mathrm{Hb})$, TLC, DLC and RBC indices were done using Diagnour Lablife H3D Premier Automated Haematology analyser. Serum iron was estimated using a colorimetric method (Ferrozine) using iron and TIBC kit adapted to VITROS 250 Autoanalyser. UGI endoscopy was performed with Olympus GIF-X-Q20 Fiberoptic Gastroscope and multiple biopsy samples were taken from antral mucosa for RUT and histopathology examination.

Compliance to treatment was assessed using pill count and empty blister foils. Response to therapy was monitored using complete haemogram, red cell indices, reticulocyte count, peripheral smear and serum iron at the end of every month in the followup visits for next three months. S. ferritin was repeated only at the end of study after three months.

All statistical data were analysed by using SPSS software version 16 statistical package for windows (Chicago, Inc.). Continuous variables were expressed as mean \pm standard deviation (Gaussian distribution) or range and qualitative data was expressed as percentage. ANOVA or analysis of variance with Tukey's post-hoc analysis was used for comparing data between groups. Categorical variables were compared using Chi squared test. All 'p' values were two 
tailed and values of $\mathrm{p}<0.05$ was considered statistically significant. All confidence intervals were calculated at $95 \%$ level.

\section{RESULTS}

102 patients, $68(66.66 \%)$ females and 34 (33.33\%) males were recruited for the study after making a diagnosis of Iron deficiency anaemia (IDA). They were subjected to endoscopic examination after written consent; 76 patients $(74.50 \%)$ of them were found to be positive for Helicobacter pylori $(\mathrm{H}$ Pylori) after Rapid urease test (RUT) and Histopathological staining.

Among these 76 patients 4 patients did not give consent for the study; 3 patients with presence of occult blood in the stool; 2 patients with hookworm on stool examination and 2 patients with gastric ulcer were excluded from the study; 3 patients developed dyspepsia due to anti-H. pylori therapy and discontinued therapy and 2 developed intolerance to oral iron therapy and were later excluded from the study.

Finally, the study was successfully carried out with 60 patients, of which 24 patients $(40 \%)$ were male and 36 patients $(60 \%)$ were female.

These 60 patients recruited in the study were randomly divided into three groups with 20 patients in each group matched for age and gender.

Age and sex distribution of study subjects are shown in Figure 1. Baseline parameters are described in Table 1.

Mean $\mathrm{Hb}$ of different groups at the beginning of our study are comparable to each other ( $p>0.05)$. At the end of first month, comparing mean $\mathrm{Hb}$ of Group 1 with Group 2 and Group 3 shows that there is significant increase in $\mathrm{Hb}$ in
Group $1(p=0.05)$. Hence, it shows that only addition of antiH. pylori therapy also improves Hb. Now comparing Group 2 with Group 3 at the end of first month does not show significant increase in $\mathrm{Hb}$ only with oral iron therapy $(\mathrm{p}>$ 0.05) (Table 2 and 3).

At the end of our study, we observed that there is significant increase in $\mathrm{Hb}$ in Group 1 and Group 2 compared to Group $3(\mathrm{p}<0.001)$ (Table 2 and 3). Maximum improvement in $\mathrm{Hb}$ was observed in Group 2 and it was significant compared to Group 1 and Group 3 (p < 0.001) (Table 2 and 3).

Patients on iron and anti-H. pylori therapy showed significantly higher increment in Haemoglobin levels, Serum iron and Ferritin at the end of treatment. Parameters after 3 months of treatment are shown in Table 4. Statistical comparison of haemoglobin levels are shown in table 3.

Endoscopic observations: We observed that in patients with very severe anaemia, i.e. Hb level less than $7 \mathrm{gm} \%$, most common endoscopic finding was Pangastritis $(n=17$, 44.73\%) followed by Atrophic Gastritis ( $\mathrm{n}=11,28.94 \%$ ). There were total 9 patients $(n=9,15 \%)$, among the 60 patients in the study who had normal endoscopic finding and all of them had haemoglobin level above $7 \mathrm{gm} \%$. We also observed in our study that the most common endoscopic finding, overall in patients with IDA and $\mathrm{H}$. pylori infestation was Pangastritis ( $n=20,33.33 \%$ ).

Severe anaemia was much more common in patients with gastritis as compared to normal individuals (Pearson chisquare was $11.318, \mathrm{p}=0.001$ ).

\begin{tabular}{|c|c|c|c|c|c|c|c|}
\hline & Hb (gm\%) & MCV (fl) & MCH (pg) & MCHC (g/dL) & Reti. (\%) & S. Fe (mcg/dL) & S. Ferritin (ng/mL) \\
\hline Group 1 & $6.78 \pm 1.32$ & $70.30 \pm 2.92$ & $20.55 \pm 4.04$ & $27 \pm 1.65$ & $0.9 \pm 0.43$ & $35.80 \pm 10.38$ & $11.45 \pm 1.70$ \\
\hline Group 2 & $6.99 \pm 1.84$ & $72 \pm 4.89$ & $22.3 \pm 3.09$ & $27.35 \pm 1.84$ & $0.8 \pm 0.59$ & $36.10 \pm 10.60$ & $12.70 \pm 2.17$ \\
\hline Group 3 & $6.61 \pm 1.32$ & $69.4 \pm 3.95$ & $20.6 \pm 3.31$ & $26.3 \pm 2.59$ & $0.8 \pm 0.2$ & $38.65 \pm 7.44$ & $12.05 \pm 1.60$ \\
\hline \multicolumn{8}{|c|}{ Table 1. Mean Baseline Parameters at the Beginning of Treatment } \\
\hline
\end{tabular}

\begin{tabular}{|c|c|c|c|c|c|c|c|}
\hline Groups & $\begin{array}{c}\text { Baseline } \\
\mathrm{Hb}\end{array}$ & $\begin{array}{l}\text { After 1st } \\
\text { Month }\end{array}$ & $\begin{array}{c}\text { Increment } \\
\text { after } 1^{\text {st }} \text { Month } \\
\text { (P value) }\end{array}$ & $\begin{array}{l}\text { After 2nd } \\
\text { Month }\end{array}$ & $\begin{array}{c}\text { Increment } \\
\text { after } 2^{\text {nd }} \text { Month } \\
\text { (P value) }\end{array}$ & $\begin{array}{l}\text { After } 3^{\text {rd }} \\
\text { Month }\end{array}$ & $\begin{array}{c}\text { Increment } \\
\text { after } 3^{\text {rd }} \text { Month } \\
\text { (P value) }\end{array}$ \\
\hline Group 1 & $6.78 \pm 1.32 \mathrm{SD}$ & $8.39 \pm 1.06 \mathrm{SD}$ & $1.61(<0.0001)$ & $9.98 \pm 0.88 \mathrm{SD}$ & $3.2(<0.0001)$ & $11.14 \pm 0.81 S D$ & $4.36(<0.0001)$ \\
\hline Group 2 & $6.99 \pm 1.84 \mathrm{SD}$ & $7.52 \pm 1.85 \mathrm{SD}$ & $0.53(0.3875)$ & $10.20 \pm 1.44 \mathrm{SD}$ & $3.21(<0.0001)$ & $12.55 \pm 1.09 \mathrm{SD}$ & $5.56(<0.0001)$ \\
\hline Group 3 & $6.61 \pm 1.32 \mathrm{SD}$ & $7.07 \pm 1.12 \mathrm{SD}$ & $0.46(0.3038)$ & $7.55 \pm 1.08 \mathrm{SD}$ & $0.94(0.0174)$ & $7.96 \pm 0.96 \mathrm{SD}$ & $1.36(0.0006)$ \\
\hline
\end{tabular}

Table 2. Mean Increment in Haemoglobin at the End of Every Month of Treatment

\begin{tabular}{|c|c|c|c|c|c|}
\hline \multirow{2}{*}{ Depend. Variable } & \multirow{2}{*}{ (I) Group } & \multirow{2}{*}{ (J) Group } & \multirow{2}{*}{ Sig. } & \multicolumn{2}{|c|}{ 95\% Confidence Interval } \\
\hline & & & & Lower Bound & Upper Bound \\
\hline \multirow{3}{*}{ Hb Baseline } & \multirow{2}{*}{$\begin{array}{c}\text { Group 1 } \\
\text { [Group 1] }\end{array}$} & Group 2 & .895 & -1.3688 & .9388 \\
\hline & & Group 3 & .933 & -.9838 & 1.3238 \\
\hline & Group 2 & Group 3 & .703 & -.7688 & 1.5388 \\
\hline \multirow{3}{*}{$\mathrm{Hb}$ after $1^{\text {st }}$ Month } & \multirow{2}{*}{$\begin{array}{c}\text { Group 1 } \\
\text { [Group 1] }\end{array}$} & Group 2 & .058 & -.1904 & 1.9304 \\
\hline & & Group 3 & .056 & .2596 & 2.3804 \\
\hline & Group 2 & Group 3 & .567 & -.6104 & 1.5104 \\
\hline \multirow{3}{*}{$\mathrm{Hb}$ after $2^{\text {nd }}$ Month } & \multirow{2}{*}{$\begin{array}{c}\text { Group 1 } \\
\text { [Group 1] }\end{array}$} & Group 2 & .822 & -1.1061 & .6661 \\
\hline & & Group 3 & $<.001$ & 1.5389 & 3.3111 \\
\hline & Group 2 & Group 3 & $<.001$ & 1.7589 & 3.5311 \\
\hline \multirow{3}{*}{$\mathrm{Hb}$ after $3^{\text {rd }}$ Month } & \multirow{2}{*}{$\begin{array}{c}\text { Group 1 } \\
\text { [Group 1] }\end{array}$} & Group 2 & $<.001$ & -2.1455 & -.6745 \\
\hline & & Group 3 & $<.001$ & 2.4445 & 3.9155 \\
\hline & Group 2 & Group 3 & $<.001$ & 3.8545 & 5.3255 \\
\hline
\end{tabular}




\begin{tabular}{|c|c|c|c|c|c|c|c|}
\hline Group & Hb (gm\%) & MCV (fl) & MCH (pg) & MCHC (g/dl) & Reti. (\%) & S. Fe (mcg/dl) & $\begin{array}{c}\text { S. Ferritin } \\
\text { (ng/mL) }\end{array}$ \\
\hline Group 1 & $11.14 \pm 0.81$ & $84.7 \pm 2.36$ & $28.25 \pm 2.53$ & $33.55 \pm 1.05$ & $1.40 \pm 0.32$ & $54.15 \pm 5.68$ & $50.1 \pm 12.73$ \\
\hline Group 2 & $12.55 \pm 1.09$ & $83.3 \pm 2.17$ & $29.85 \pm 2.90$ & $35.75 \pm 0.96$ & $1.04 \pm 0.25$ & $73.85 \pm 8.64$ & $99.2 \pm 33.20$ \\
\hline Group 3 & $7.96 \pm 0.96$ & $75.3 \pm 4.26$ & $25.05 \pm 2.18$ & $29.9 \pm 1.55$ & $1.24 \pm 0.30$ & $48.55 \pm 6.76$ & $21.25 \pm 6.43$ \\
\hline \multicolumn{7}{|c|}{ Table 4. Mean Parameters at the End of Treatment } \\
\hline
\end{tabular}

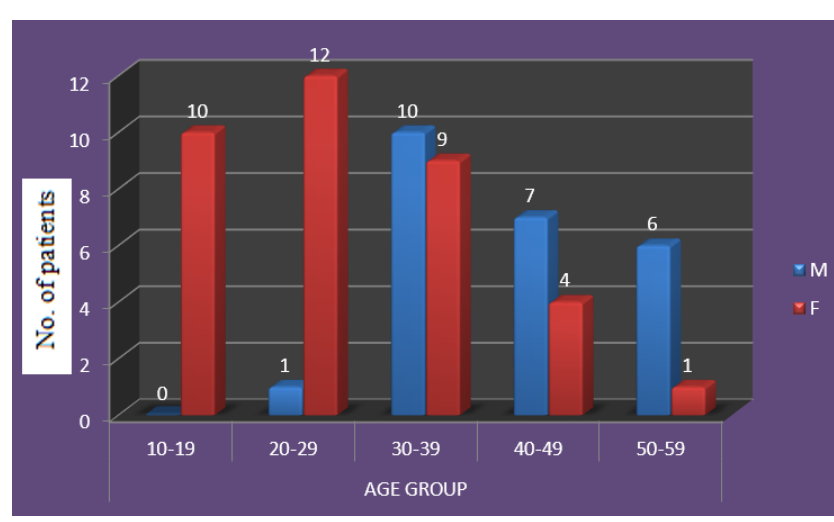

Figure 1. Distribution of Study Subjects according to Sex and Age

\section{DISCUSSION}

Several studies have implicated $\mathrm{H}$. pylori infection as a cause of refractory IDA in patients with no intestinal blood loss, poor intake or malabsorption.4,5 Various mechanisms have been hypothesised to explain the possible effect of $\mathrm{H}$. pylori infection on iron stores. It appears that chronic gastrointestinal blood loss is not the likely culprit, since most published cases and case series found no bleeding lesions after investigation and the subjects had negative faecal occult blood testing.6,7 A more likely mechanism is decreased iron absorption from hypo or achlorhydria resulting from chronic gastritis. ${ }^{8}$ Person with H. pylori infection and IDA appear more likely to have corpus gastritis as compared to $\mathrm{H}$. pylori infected patients without anaemia, which results in decreased gastric acid secretion and increase in intragastric $\mathrm{pH}$ that may impair iron absorption.9,10 Another important effect of $\mathrm{H}$. pylori gastritis that may cause reduced iron absorption is a decrease in gastric juice ascorbic acid concentration,11,12 increased hepcidin production from hepatocytes in response to IL-6 production associated with H. pylori gastritis. ${ }^{13}$

Another hypothesised mechanism to explain an association between $\mathrm{H}$. pylori infection and iron deficiency is uptake of iron by the $\mathrm{H}$. pylori organism controlled by the ferric uptake regulator gene product (Fur), ${ }^{14}$ but why few and not all patients of $\mathrm{H}$. pylori gastritis develop IDA is not clear and it opens a window for further more studies. Sequestration of iron in lactoferrin in the gastric mucosa is also suggested as possible. ${ }^{15,16}$

In our study, 76 of 102 (74.50\%) patients with IDA were H. pylori positive. Majority of the cases $(53.32 \%)$ were in the age group of 20 - 39 years. The cases in the age group of less than 20 years and more than 40 years were $16.66 \%$ and $18.33 \%$ respectively. The sero-prevalence studies from Hyderabad, Mumbai ${ }^{17,18}$ have shown that by 10 years of age more than $50 \%$ and by 20 years more than $80 \%$ of population is infected with H. pylori. Another study from Bangalore ${ }^{19}$ has detected $\mathrm{H}$. pylori infection in $82 \%$ of 50 children ( 6 to 18 years of age).
Majority of the patients $66.66 \%$ (68 of 102) of iron deficiency anaemia were female in our study and between the age of 20 to 39 years thereby showing the increased quantum of IDA in female in this area and that too in reproductive age. An interesting observation was that there were 10 patients less than 20 years of age and all of them were female, so it seems females in adolescence are the most vulnerable group for anaemia. We also observed that there are 38 patients below haemoglobin $7 \mathrm{gm} \%$ and 29 (76.31\%) of them are female. There are many causes, especially in a developing country like India for increased prevalence of IDA in females in their child bearing age. National Family Health Survey (NFHS-3) reveals the prevalence of anaemia to be 70\% - 80\% in children, $70 \%$ in pregnant women and $24 \%$ in adult men. Prevalence of anaemia in India may be high because of low dietary intake, poor availability of iron and chronic blood loss due to hook worm infestation and malaria.

All the patients were subjected to detailed oesophagogastroduodenoscopic examination. The most common endoscopic finding in our study was Pangastritis (33.33\%). Similarly, high prevalence of Pangastritis was observed in a study conducted by Brunno Annibale et al, where $80 \%$ of the patients with IDA and H. pylori infection had Pangastritis. ${ }^{20}$ Person with H. pylori infection and IDA appear more likely to have corpus gastritis as compared to $H$. pylori infected patients without anaemia. ${ }^{9}$

Another important finding observed in our study was related to endoscopic finding and severity of anaemia. We found a significant association between gastritis and anaemia.

Observed the overall rise in $\mathrm{Hb}$ at the end of our study was maximum for Group 2 and it was $5.56 \mathrm{gm} \%$, followed by Group 1 where it was 4.36 gm\% and minimum for Group 3 $1.35 \mathrm{gm} \%$.

At the end of first month, the rise in Haemoglobin in Group 2 and Group 3 were not significant $(0.53$ gm $\%$ and $0.46 \%$ respectively, $\mathrm{p}=>0.05$ ). After addition of anti-H. pylori therapy to Group 2 in the beginning of second month we found that the mean increase in Haemoglobin at the end of second month in Group 2 and Group 3 a significant improvement in the Haemoglobin level was observed from the baseline $\mathrm{Hb}$ level $(3.21$ gm\% and 0.94 gm\% respectively, $\mathrm{p}<0.05$ ). Authors like Valiyaveettil et $\mathrm{al}^{21}$ has demonstrated significantly greater rise in haemoglobin level after anti-H. pylori therapy compared with those who received only iron supplementation.

Improvement in $\mathrm{MCH}$ and $\mathrm{MCHC}$ was maximum in Group 2 (13.45 pg). We found that in Group 1, MCV improved minimally in group 1 . The mean increase in serum ferritin at the end of three month was $38.55 \mathrm{ng} / \mathrm{mL}$, in Group 2 was $86.3 \mathrm{ng} / \mathrm{mL}$, but in Group 3 the rise was only $9.2 \mathrm{ng} / \mathrm{mL}$. It is implied that anti-H. pylori therapy helps in increasing the serum ferritin level, thereby improving body iron store.

Epidemiologic studies have shown that persons seropositive for $\mathrm{H}$. pylori infection have a significantly lower 
serum ferritin level.22 In a population-based study from Denmark, H. pylori-seropositive persons were at $40 \%$ increased risk of having reduced serum ferritin level $(<30$ $\mathrm{mg} / \mathrm{L}$ ) compared to seronegative individuals (after adjustment for age, gender, menopausal status, socioeconomic status, blood donation and alcohol consumption). ${ }^{23}$ Analysis of a cross-sectional national health survey from Germany $(n=1806)$ revealed that persons with H. pylori infection had $17 \%$ decrease $(95 \%$, CI 9.8 - 23.6) in serum ferritin concentration after adjustment for age and sex. ${ }^{24}$

In Group 3, we found that the mean increase in the serum iron at the end of 3 months was $9.9 \mathrm{mcg} / \mathrm{dL}$, whereas in Group 1 and Group 2 it was $18.35 \mathrm{mcg} / \mathrm{dL}$ and $37.75 \mathrm{mcg} / \mathrm{dL}$ respectively. It shows that addition of anti-H. pylori therapy significantly improves serum iron level in Group 1 and Group 2.

\section{CONCLUSION}

This study is definitely suggesting significant role of chronic $\mathrm{H}$. pylori gastritis as a cause of refractory IDA. We have observed that in majority of the cases of refractory IDA chronic $\mathrm{H}$. pylori infection has been found and in such cases the resolution of anaemia was possible with eradication of H. pylori infection. Therefore, we suggest in all cases of refractory or chronic IDA, patient must be investigated for the presence of $\mathrm{H}$. pylori gastritis.

\section{ACKNOWLEDGEMENTS}

- Prof. MR Ajmal, MD (General Medicine) Professor, Department of Medicine, JN Medical College and Hospital, AMU, Aligarh,

- Prof. Shamshad Ahmad, MD (Pathology), Professor, Department of Pathology, JNMCH, AMU, Aligarh.

- Prof. Indu Shukla, MD (Microbiology), Professor, Department of Microbiology, JNMCH, AMU, Aligarh.

- Prof. HS Khan, MD (General Medicine), Professor, Department of Medicine, JNMCH, AMU, Aligarh,

\section{REFERENCES}

[1] Iron deficiency anaemia. World Health Organisation 2007.

[2] Prevention and control of iron-deficiency anaemia in women and children. Report of the UNICEF/WHO Regional Consultation Feb, 1999.

[3] Maternal and child undernutrition. The Lancet Series and Indian Perspective. Indian Pediatrics 2008;45:298-9.

[4] Dufour C, Brisigotti M, Fabretti G, et al. Helicobacter pylori gastric infection and sideropenic refractory anemia. J Pediatr Gastroenterol Nutr 1993;17(2):2257.

[5] Barabino A. Helicobacter pylori-related iron deficiency anemia: a review. Helicobacter 2002;7(2):71-5.

[6] Marignani M, Angeletti S, Bordi C, et al. Reversal of long-standing iron deficiency anaemia after eradication of Helicobacter pylori infection. Scand J Gastroenterol 1997;32(6):617-22.

[7] Kostaki M, Fessatou S, Karpathios T. Refractory irondeficiency anaemia due to silent Helicobacter pylori gastritis in children. Eur J Paediatr 2003;162(3):177-9.
[8] Lombard M, Chua E, O'Toole P. Regulation of intestinal non-haem iron absorption. Gut 1997;40(4):435-9.

[9] Capurso G, Lahner E, Marcheggiano A, et al. Involvement of the corporal mucosa and related changes in gastric acid secretion characterize patients with iron deficiency anaemia associated with Helicobacter pylori infection. Aliment Pharmacol Ther 2001;15(11):1753-61.

[10] Annibale B, Capurso G, Lahner E, et al. Concomitant alterations in intragastric $\mathrm{pH}$ and ascorbic acid concentration in patients with Helicobacter pylori gastritis and associated iron deficiency anaemia. Gut 2003;52(4):496-501.

[11] Zhang ZW, Patchett SE, Perrett D, et al. The relation between gastric vitamin $\mathrm{C}$ concentrations, mucosal histology and CagA seropositivity in the human stomach. Gut 1998;43(3):322-6.

[12] Sobala GM, Schorah CJ, Shires S, et al. Effect of eradication of Helicobacter pylori on gastric juice ascorbic acid concentrations. Gut 1993;34(8):1038-41.

[13] Pellicano R, Rizzetto M. Is hepcidin the bridge linking Helicobacter pylori and anemia of chronic infection? A research proposal. Panminerva Med 2004;46(3):1659.

[14] Barabino A, Dufour C, Marino CE, et al. Unexplained refractory iron-deficiency anemia associated with Helicobacter pylori gastric infection in children: further clinical evidence. J Pediatr Gastroenterol Nutr 1999;28(1):116-9.

[15] Choe YH, Oh YJ, Lee NG, et al. Lactoferrin sequestration and its contribution to iron-deficiency anemia in Helicobacter pylori-infected gastric mucosa. J Gastroenterol Hepatol 2003;18(8):980-5.

[16] Nakao K, Imoto I, Gabazza EC, et al. Gastric juice levels of lactoferrin and Helicobacter pylori infection. Scand J Gastroenterol 1997;32(6):530-4.

[17] Graham DY, Adam E, Reddy GT, et al. Seroepidemiology of Helicobacter pylori infection in India: comparison of developing and developed countries. Dig Dis Sci 1991;36(8):1084-8.

[18] Gill HH, Majmudar P, Shankaran K, et al. Age-related prevalence of Helicobacter pylori antibodies in Indian subjects. Indian J Gastroenterol 1994;13:92-9.

[19] Dore SP, Krupadas S, Borgonha S, et al. The 13C urea breath test to assess Helicobacter pylori infection in school children. Natl Med J India 1997;10(2):57-60.

[20] Annibale B, Marignani M, Monarca B, et al. Reversal of iron deficiency anemia after Helicobacter pylori eradication in patients with asymptomatic gastritis. Ann Intern Med 1999;131(9):668-72.

[21] Valiyaveettil AN, Hamide A, Bobby Z, et al. Effect of anti-Helicobacter pylori therapy on outcome of irondeficiency anemia: a randomized, controlled study. Indian J Gastroenterol 2005;24(4):155-7.

[22] Parkinson AJ, Gold BD, Bulkow L, et al. High prevalence of Helicobacter pylori in the Alaska native population and association with low serum ferritin levels in young adults. Clin Diagn Lab Immunol 2000;7(6):885-8. 
[23] Milman N, Rosenstock S, Andersen L, et al. Serum ferritin, hemoglobin and Helicobacter pylori infection: a seroepidemiologic survey comprising 2794 Danish adults. Gastroenterology 1998;115(2):268-74.
[24] Berg G, Bode G, Blettner M, et al. Helicobacter pylori infection and serum ferritin: a population-based study among 1806 adults in Germany. Am J Gastroenterol 2001;96(4):1014-8. 